\title{
FACTORES CONDICIONANTES DE LA EVOLUCION DEMOGRAFICA DE ALICANTE DURANTE LA PRIMERA MITAD DEL SIGLO XIX
}

\author{
Miguel Angel Esteve González
}

\section{1. - INTRODUCCION}

A lo largo del presente estudio expondremos las causas del estancamiento alicantino durante la primera mitad del siglo $X I X$, destacando fundamentalmente las sequías, crisis de subsistencias, epidemias y estado sanitario de la población.

En este sentido cabe decir que el período comprendido entre 1802 y 1838 comenzó con una aguda crisis de subsistencia motivada fundamentalmente por la escasez de trigo. En 1804 hubo una fuerte sequía y, lo que es peor, una epidemia de fiebre amarilla, declarada en septiembre y que, como ya expondremos y desarrollaremos más adelante, causó un elevado número de víctimas. Entre los años 1806 y 1810 se padeció una pertinaz sequía que, unida a los problemas provocados por la guerra de la Independencia afectó seriamente a la población. En 1811 las contribuciones de guerra, la aglomeración de gentes como consecuencia de la proximidad del ejército francés, así como un brote epidémico de fiebre amarilla, preocuparon al Municipio. En los años comprendidos entre 1813 y 1829 son casi permanentes las referencias capitulares a la falta de lluvias, aunque no se menciona generalmente la posible pérdida de las cosechas. En 1822 un brote de viruelas hace que se active la vacunación de los niños y en 1829 el Ayuntamiento señala el estado de miseria general y la continua emigración de los vecinos. Alicante se despoblaba. 
En el quinquenio 1839-1834 la sequía fue espantosa y los problemas se agravan con la epidemia de cólera de 1834. En 1836 las vicisitudes de la guerra carlista motivaron que innumerables familias corrieran a protegerse en los muros de la ciudad. En 1838 el pillaje se enseñoreó de la huerta y campo de la ciudad y el Cabildo acordó crear guardas de campo sin sueldo.

La década de los cuarenta fue particularmente nefasta para la ciudad. En 1841 se perdieron todas las cosechas. En 1843 se señala el estado de miseria de la población y la emigración al extranjero (Argelia). En 1847 se constata el paro de los jornaleros y el alto precio del trigo por lo que el Ayuntamiento permitió la entrada de grano extranjero. En la década de los cuarenta se produjo el ocaso definitivo de la barrilla, uno de los principales soportes de la economía alicantina, junto con la exportación de vinos, que también sufrió un fuerte descenso. El año 1851 sería el primero, después de muchos, en que se daría una cosecha regular.

\section{2. - LA EVOLUCION DEMOGRAFICA DE ALICANTE ENTRE 1803 Y 1850}

En 1803 Alicante tenía 17.672 habitantes (1). En 1804 el número total de vecinos era de 3.977 (2). Si dividimos las dos cifras anteriores resulta un coeficiente de 4,4 personas por vecino. La epidemia de fiebre amarilla iniciada en septiembre de 1804 y posterior a estos recuerdos causó 2.765 defunciones en la ciudad y sus arrabales (3). En diciembre de 1834 el municipio contaba con 4.748 vecinos y 21.260 almas, siendo el coeficiente de 4,4 personas por vecino, igual, por tanto, al de comienzos de siglo. El número de fallecidos por la epidemia de cólera del año mencionado ascendió a 830 (4). La tasa de crecimiento medio anual entre 1803 y 1834 fue del $0,59 \%$.

En 1840 la ciudad tenía 18.123 habitantes, 3.137 menos que en 1834 (5). En 1842 la cifra baja a 17.857, número ligeramente superior al de 1803. En 1847 la población de hecho asciende a 19.224 individuos y, en 1850, Alicante contaba con 19.650 personas. Observamos que no se superan las cifras de 1834 que, por otra parte, son posteriores a la epidemia de cólera de dicho año.

(1) A(rchivo) M(unicipal) de A(licante): Respuestas al Interrogatorio de 1802.

(2) MAS Y GIL, L.: "Informe incompleto sobre Alicante, año 1804».

(3) JOVER, N.C.: "Reseña histórica de la ciudad de Alicante», pág. 112.

(4) A.M.A. Libro de Actas 124. Enero de 1835.

(5) B(oletín) O(ficial) de la P(rovincia). 7 de Diciembre de 1840. 
La tasa de crecimiento medio anual entre 1803 y 1850 fue del $0,22 \%$, muy baja si tehemos en cuenta que entre 1803 y 1900 dicha tasa fue del $0,98 \%$. Aun teniendo en cuenta la posible falta de exactitud de los datos utilizados, pues no podemos olvidar que nos encontramos en una época preestadística, queda claro que las cifras de población indican un estado de estancamiento demográfico, más evidente durante la década de los cuarenta.

\section{3. - CONDICIONES DE LA EVOLUCION DEMOGRAFICA}

\section{1. - ANALISIS GENERAL}

La ciudad de Alicante al inicio del siglo XIX seguía siendo un centro comercial muy importante, como lo fue durante el siglo XVIII. La ciudad poseía dos condiciones favorables para ello: la excepcionalidad de su puerto y la facilidad de sus comunicaciones con Madrid. El estancamiento y atonía de la ciudad en la centuria decimonónica sólo puede ser comprendido entre otras causas por el hecho de ser una ciudad con una función dominante, la comercial, con el complemento casi único de una agricultura no volcada a la producción de artículos para el consumo del núcleo urbano, sino imbricada en la red comercial que el puerto tejía (6). Así el entorno rural de la ciudad dedica sus tierras más rentables a cultivos estrechamente vinculados al comercio como la viticultura, relegando cultivos con gran incidencia en el consumo urbano, como el cereal, cuyos rendimientos son muy inferiores al no hallarse adaptados a las condiciones climáticas. El déficit triguero se cubre con el grano ultramarino o con el que transportan los arrieros manchegos en sus viajes de ida. Cuando los caminos del mar se interrumpen, el mecanismo de la ciudad, sustentado por un equilibrio frágil, pasa por graves quebrantos. Aislada de las rutas comerciales que su situación permite, la ciudad pierde su pulso y languidece (7).

La primera mitad del siglo XIX comienza y finaliza en Alicante con sendas crisis de subsistencias comparables con las del siglo anterior. Las epidemias de fiebre amarilla y cólera de los años 1804 y 1834 supusieron una pérdida importante de efectivos demográficos y contribuyeron a la desorganización de las distintas actividades de la ciudad. La guerra de la Independencia sobrepobló artificialmente el término muni-

(6) GIMENEZ, E.: «Alicante en el siglo XVIII», pag. 14.

(7) GIMENEZ, E.: Op. cit. pág. 32 y 33. 
cipal y favoreció la carestía de víveres. Enfermedades como la viruela diezmaban la población infantil. Los establecimientos sanitarios sólo existían norminalmente pues, de hecho, carecían de espacio, no funcionaban adeccuadamente y rara vez recibían regularmente la subvención municipal. Por otro lado la mentalidad de la población era la de asumir la enfermedad como una fatalidad y desconfiar de los médicos que eran sustituidos en general por los barberos y otros intrusos. Este estado de opinión se reforzó por la impotencia de los facultativos durante las epidemias de 1804 y 1834.

Desde el punto de vista comercial, la exportación de la barrilla pronto decae hasta desaparecer y los vinos no encuentran demanda en el exterior. La solución a todos estos problemas era la emigración y, efectivamente, a partir de 1830 y, sobre todo durante los años cuarenta, ésta llega a ser muy importante. La zona elegida será la de Orán-Argel, ya conocida trádicionalmente por los alicantinos. El abastecimiento de trigo para Alicante procedía de Andalucía, la Mancha y Castilla. En caso de gravedad se planteaba la posibilidad de importar grano extranjero. Como podremos observar las situaciones límite se darán con frecuencia.

Los factores anteriormente citados, unos de tipo estructural y otros más coyunturales, explican el estancamiento poblacional de la ciudad durante la primera mitad del siglo XIX.

\section{2. - LOS AÑOS 1800-1806: CRISIS DE SUBSISTENCIAS Y EPIDEMIA DE 1804}

En el libro de cabildos con fecha 12 de mayo de 1800, leemos: «...Teniendo presente sus señorías los perjuicios que ocasiona a la salud pública el fetor que se experimenta en las balsas y balsicas de los huertos inmediatos por no limpiarse de continuo según deben hacerlo los dueños o arrendadores y también por permitirse lavar en ellos ropas, sus señorias acordaron, que se repitan los pregones para que desde luego se limpien las balsicas, continuando esta operación cada quince días mientras dure el verano, sin permitir se lave en ellas ropa alguna» (8).

El 17 de septiembre de dicho año se vuelve a insistir sobre la limpieza de las balsas $y$, además, se ordena: «...se llame al capataz de basureros y se le prevenga que él y su compañía deben tener limpias las calles y sitios de donde sacan su utilidad» (9).

(8) A.M.A. Libro 95.

(9) Ibid. 
En la reunión del Cabildo de 20 de octubre del mismo año, sus señorías tienen en cuenta la epidemia que se está produciendo en Cádiz y otros pueblos de Andalucía y determinan que, en caso de necesidad, sería necesaria la acción de un médico más aparte de los tres titulares que tiene la ciudad. Su obligación era uasistir por turno al cuidado de los pobres y enfermos de esta ciudad, Hospital de San Juan de Dios y de la cárcel, como igualmente a cuanto se le prevenga en las actuales críticas circunstancias y otras que puedan ocurrir» (10).

El año 1802 se caracterizó por la escasez de trigo. En el Cabildo Municipal del 23 de marzo se constata: «...el apuro de la ciudad en el preciso y principal abasto del pan por la extremada escasez de granos por las cercanias» (11). El corregidor exigió de un importante comerciante que aportara cuanto tuviese en sus almacenes y despachó un barco para Orán con Pliego para el Bey, suplicándole la remesa de más trigo. El 28 de marzo fondea en la bahía de Alicante un barco cargado de trigo que llevaba rumbo a Barcelona. El gobernador convoca al Cabildo y que plantea la posibilidad de intervenir el cargamento, ante las interrupciones de varios carruajes de trigo dentro de la provincia por lo que «se puede recelar con seguridad, la ninguna esperanza que tiene este pueblo de dicho abastecimiento del interior». Después de discutir sobre la conveniencia o no de detener el barco acuerdan no hacerlo ya que había trigo para quince días más y la necesidad no era perentoria. pero el 6 de Abril, teniendo noticia el gobernador de hallarse fondeado en el puerto el buque Raguseo con carga de trigo, se permitió a unos comisionados hacer acopio de hasta 2.000 cahíces. El 26 de abril se acuerda traer trigo de Sevilla, porque no llegan los barcos. También se decide hacer pan de munición para los pobres y el común.

El 5 de mayo el señor gobernador presidente se sirve mandar la detención y descargo de las 600 fanegas de trigo de un barco fondeado en Alicante, con destino a Barcelona. Esto se hace sin perjuicio en cuanto al precio del corriente en Barcelona o al que pueda convenir con el interesado (12). El 13 de mayo se soluciona el problema debido al arribo de distintos barcos y se suspende la petición de trigo que se hizo a Sevilla.

1804 será un año aciago para Alicante. En septiembre hace su aparición una epidemia de fiebre amarilla, atribuyéndose su importación, según Viravens (13), a un contrabando de géneros que se introdujo en la

(10) Id.

(11) A.M.A. Libro 97.

(12) A.A.A. Libro 97.

(13) VIRAVENS Y PASTOR, R.: «Crónica de la Muy llustre y Siempre Fiel ciudad de Alicante), 1876, pág. 344. 
casa de un comerciante alicantino. Para Jover el contagio fue importado por un buque de guerra español procedente de Las Antillas. En vano se tomaron por las autoridades y por la Junta de Sanidad las más extremas precauciones y, en vano se mandó cerrar el puerto desde el día 21, cortando así toda comunicación que pudiera ser perniciosa. El 24 se tapiaron muchas calles contagiadas y los enfermos eran trasladados al lazareto que, desde el día 17 se había establecido en el convento de San Francisco. "El día 24 por la noche, a fin de calmar el pánico que se había apoderado de todo el mundo, se trajo y se paseó por la ciudad en solemne rogativa, la venerada reliquia de la Santa Faz, subiéndola después al castillo, en dórıde permaneció todo el tiempo del contagio, que duró hasta el 24 de Diciembre. El Te-Deum en acción de gracias por la completa desaparición de la enfermedad no se cantó hasta el 27 de enero de 1805, y aunque por el estado general de enfermos y muertos que se comunicó oficialmente al gobierno sólo constan 2472 defunciones, el número de muertos en la ciudad y arrabales ascendió a 2765» (14).

Las actas capitulares de los dos primeros meses de 1805 reflejan las consecuencias de la epidemia del año anterior. $Y$ así encontramos una cantidad elevada de memoriales de gentes necesitadas que piden ayu$\mathrm{da}$, y de opositores de plazas dejadas vacantes por el contagio, ya sean de médico, abogado, ministro de capilla, notaría e incluso para pregonero. También hay memoriales firmados por diversos abastecedores de carne. Así en memorial del 18 de febrero, el abastecedor de carne del caserío de la Santa Faz, jurisdicción de la ciudad, expone que el abasto se concluyó con motivo de haberse abrigado infinitas familias de Alicante durante el contagio. Otro de los memoriales, fechado el 21 de mayo, es el del encargado de abastos en San Vicente del Raspeig, y expone que, desde 1804, ha surtido de carnes tanto a los moradores de dicho caserío como a más de mil personas que emigraron en aquellos contornos $y$, por tanto, ha finalizado con todos los acopios que había hecho para todo el tiempo del abasto estipulado. Insiste, además, en la escasez de ganado debido al acordonamiento de los pueblos y pide, como el anterior, un aumento del precio de la carne (15).

En 1805 se edificó un cementerio en la partida de San Blas. El antiguo emplazamiento era la falda oeste del Benacantil. En este lugar se enterraba a los pobres, mientras que en las iglesias se enterraba a los que tenían panteones de su propiedad. Al invadir la fiebre amarilla la póblación se suspendió enterrar en las iglesias por efecto de las circunstan-

(14) JOVER, N.C.: Op. cit. pág. 112.

(15) A.M.A. Libro 100. 
cias. Desaparecidas éstas se volvió a la antigua costumbre pero el miedo a que se reprodujese la epidemia y las leyes que prohibian los enterramientos en las iglesias, obligaron al Cabildo de San Nicolás a construir un cementerio común en el lugar mencionado al principio.

Jover refiere en su reseña histórica que los emigrantes durante la epidemia fueron más de dos mil (16). Viravens por su parte afirma que los habitantes que se contaban en la ciudad ascendían a 13.212 antes de aparecer la epidemia. De éstos emigraron 2.110, quedando reducido el vecindario a 10.740 cuando cesó el contagio (17).

En el Cabildo celebrado el 8 de octubre de 1805 se leyó una Real Orden mandando que se levantasen los cordones sanitarios, se quitaran las cuarentenas que tenían oprimido al comercio interior y se cantase el Te-Deum por la completa desaparición del contagio en todos los pueblos de la península (18).

\section{3. - 1807-1814: INCIDENCIA DE LA GUERRA Y LAS MEDIDAS DE HIGIENE}

Los primeros años de este período se caracterizan por la escasez de lluvias. El año 1810 inicia un período difícil para Alicante. El día 9 de abril el Ayuntamiento acuerda celebrar rogativas para implorar la tan apetecida lluvia. Por otro lado los movimientos estratégicos de las tropas francesas mandadas por Suchet, en el Reino de Valencia, obligaron ese mismo mes al general Freire a acantonarse en Alicante con la división que mandaba del ejército de Blake. A la vez que entraron en esta ciudad las legiones de Freire, vinieron también muchas familias de los pueblos y comarcas circunvecinas, ocasionando tan extraordinaria concurrencia, un gran perjuicio al vecindario, pues llamado a proveer de comestibles a tantas gentes, es evidente que consumirian los depósitos de víveres procurados para el caso de sitio (19).

El 9 de febrero de 1811 el Cabildo acuerda se realice una contribución de medio millón de reales entre los pudientes de la ciudad, «rebajados los jornaleros y otros vecinos que carecen o tienen limitadas sus facultades para sobrellevarla, siguiéndose el sistema adoptado en la epidemia de 1804 y bajo la calidad de reintegro, según y en los términos que en ella se observaron» y que, con este objeto, tenían ya formada la relación

(16) JOVER, N.C.: Op. cit., pág. 112.

(17) VIRAVENS, R.: Op. cit., pág. 346.

(18) A.M.A. Libro 100.

(19) VIRAVENS, R.: Op. cit., pág. 385. 
de pudientes. El 26 de junio se recibe un comunicado que señala que el Consejo de Regencia aprueba esta iniciativa municipal (20).

En septiembre se reprodujo la fiebre amarilla pero, tan levemente, que no pasaron de diecisiete las víctimas que hizo (21). Sin embargo un memorial firmado por varios vecinos el 10 de septiembre dice asi: «...las actuales circunstancias nos han puesto en estado de la mayor aflicción. Nos vemos circuidos por todos lados del enemigo. Las enfermedades contagiosas cunden hasta casi dentro de nuestros muros, y la actividad, diligencias y acertadas precauciones del gobierno no bastan a evitar se aproximen y por todas partes no se observan más que disposiciones que causan el mayor conflicto» (22). Los firmantes acaban solicitando una solemne rogativa que el Ayuntamiento aprueba enseguida.

El 9 de agosto de 1812 arribó a nuestra bahía una numerosa flota que desembarcó la división anglosiciliana mandada por Sir Juan Murray: componíase aquel cuerpo del ejército, destinado a operar en Cataluña, de seis mil hombres a las órdenes del teniente general $D$. Tomás Maitland, y de catorce mil infantes y setecientos caballos, todos de la división española de Whittinghan. Viravens sólo menciona a los seis mil hombres de la división anglosiciliana y afirma que estas tropas se alojaron en casas particulares, en los claustros de San Nicolás, en el Monasterio de Santa Verónica y en los pueblos circunvecinos. Sitúa, en cambio, en mayo de 1813, el arribo de ocho mil infantes y setecientos caballos que, junto a los anteriores, zarparon rumbo a Tarragona en ese mismo mes.

Tan gran afluencia de gentes atrajo a nuestra población un sin número de especuladores de toda la provincia y aun de fuera de ella. El comercio adquirió movimiento, los artículos de primera necesidad se vendian elevados, $y$, en los cuatro meses que permanecieron en Alicante los anglosicilianos, se hicieron algunas fortunas (23).

El año 1813 no presenta tampoco, desde sus inicios, perfiles muy esperanzadores. El 7 de enero se presenta un informe en el que se afirma que los enfermos existentes son 15 hombres y 28 mujeres. En él se indica que la Real Hacienda sigue suministrando los medicamentos y que los cirujanos de la tropa asisten igualmente a los paisanos, de cuyo auxilio carecerán al momento que sean trasladados a su antiguo Hospital de San Juan de Dios, lo que es imposible verificar hasta que éste se desocupe de tanta gente extranjera y tropa que lo embaraza. Igualmente se

(20) A.M.A. Libro 106.

(21) JOVER, N.C.: Op. cit., pág. 118.

(22) A.M.A. Libro 106.

(23) JOVER, N.C.: Op. cit., pág. 120. 
señala la dificultad de poder abrigar en dicho Hospital a tanto enfermo, pues se reduce a seis camas para hombres y otras tantas para mujeres. Estas cifras nos dan idea clara del estado de las instituciones sanitarias y del nulo servicio que ofrecian.

En reunión del 11 de enero, el Consistorio tiene presente el exceso de pobres mendigos forasteros que se abrigan en la ciudad contra la principios de policía y deseando evitar los males que puedan originarse y el hacinamiento en el hospital, acuerda: «que el alguacil mayor y su teniente hagan salir a cuantos se encuentren de ambos sexos y no sean naturales o vecinos de esta ciudad, y para evitar nuevas introducciones se oficia al señor gobernador militar de esta plaza para que dé la orden correspondiente a los oficiales y comandantes de los guardias de las puertas".

No se debian obedecer muy disciplinadamente las órdenes que en materia de higiene dictaba el Ayuntamiento, puesto que estas se reiteraban una y otra vez. El 21 de Febrero se publica un bando que sustancialmente prohibe tres cosas bastante fáciles de comprender como son: Verter basuras y estiércol antes de las diez de la noche y después de las diez de la mañana, abrir las cloacas de las casas y hacer las necesidades o arrojar cualquier especie de agua a la calle (24).

\section{4. - 1815-1823: SEQUIA, REFORMAS SANITARIAS Y VACUNACION.}

La sequía que se experimentó en 1815 motivó el acuerdo del Cuerpo Municipal para la traslación de la Santa Faz el día 9 de marzo. El 22 de abril del mismo año se anuncia la vacunación al público que comenzaría en el mes de mayo (25).

La pertinaz sequía siguió sembrando la destrucción en el pueblo alicantino durante 1816. El 3 de agosto un concejal presenta el triste cuadro de la miseria absoluta en que se encontraban muchas familias por la incuria del tiempo y pide que se vuelva a establecer la sopa económica para aliviar y mantener a los muchos pobres y necesitados. El Cuerpo Municipal acuerda oficiar al obispo para que también contribuya así como a los señores curas. El 19 de noviembre se acuerda realizar rogativas para implorar el beneficio de la lluvia al Todopoderoso (26). To-

(24) A.M.A. Libro 108.

(25) A.M.A. Libro 110.

(26) A.M.A. Libro 111. 
do sería en vano pues las rogativas e imploraciones siguieron durante los meses de enero y marzo de 1817 (27).

El 28 de Junio se recibe un oficio del capitán general del reino en el que vistas las malísimas condiciones de la cárcel, ordena que se trasladen a la Casa de la Asegurada el número de presos que se considere oportuno, haciéndose en las cárceles las fumigaciones que acuerden los médicos para purificar la atmósfera.

El 19 de julio el Cabildo recibe una circular de la superioridad en la que se amonesta a los pueblos a que no se resistan a vacunar a sus hijos. El documento citado pasó a la Comisión de Sanidad que era la encargada de estos asuntos (28). Esta es una muestra clara de la ignorancia de la población en las cuestiones sanitarias y de salud pública. Como demostraremos más adelante esta mentalidad retrógrada de nuestros antepasados decimonónicos se mantendría durante casi todo el siglo.

Por si el panorama no fuera suficientemente desolador, la lluvia, por la que tantas rogativas se habian hecho, llegó el 12 de octubre, pero no como agua de salvación sino de destrucción. Toda la parte baja de la población quedó inundada. Las aguas también corrieron por las vertientes del Benacantil empujando grandes peñascos y las basuras de las calles de Villavieja. Los almacenes y edificios de planta baja quedaron completamente inundados y el comercio experimentó pérdidas de gran importancia. La municipalidad, a la vista de esta situación, acuerda en reunión celebrada el 17 de octubre, pedir ayuda al Consejo de Castilla por medio del capitán general del reino (29).

Pero la sequía no perdonaba y el 23 de marzo de 1818, ante la falta de agua y lo inmediato que estaba a perderse la cosecha, la municipalidad acuerda nuevas rogativas públicas (30).

El 30 de agosto de 1821 se constituyó una Junta de Beneficencia. Como el 5 de octubre las Cortes del Reino erigieron a Alicante en capital de provincia se hacía necesario habilitar una Casa de Maternidad y que el Hospital Civil se situase en la extremidad de la población. La Corona cedió el edificio del suprimido convento de los PP. Capuchinos para que la Junta de Beneficencia estableciese en él un hospicio a fin de albergar a los pobres huérfanos y desamparados, el cual se inauguró inmediatamente (31).

Pero no sólo la sequía era el problema permanente en el período estu-

(27) A.M.A. Libro 112.

(28) A.M.A. Libro 112.

(29) Ibid.

(30) A.M.A. Libro 113.

(31) VIRAVENS, R.: Op. cit, pág. 405. 
diado hasta ahora. Si bien hemos encontrado múltiples referencias a la misma en los documentos de la época, no es menos cierto que las enfermedades infecciosas debieron ser una constante clara entre la población alicantina. Una de estas enfermedades fue la viruela. La Real Cédula de 1805 mandaba que en los hospitales de las capitales de España se destinara una sala para conservar el fluido vacuno. El Gobierno desde 1805 había recomendado a las autoridades que empleasen toda su energía con el objeto de generalizar la vacunación. Por desgracia la guerra de la Independencia relegó a segundo término el combate emprendido contra la viruela, demorando hasta 1814 el primer reglamento sobre la práctica de la vacunación, convertida en obligatoria para todos los párvulos, dentro de los dos primeros meses de vida (32).

El Cabildo municipal de 9 de marzo de 1822 da cuenta de una circular del Jefe Político en la que se ordena se practique la vacuna en la ciudad y que influyan los reverendos curas para hacer conocer a sus feligreses el bien de una medida tan filantrópica. El 21 de Mayo el Cuerpo Municipal recibe un oficio de la Junta Superior de Sanidad de ia provincia manifestando que en la capital existen algunos niños enfermos de viruelas naturales y que para atajar la propagación de tan terrible azote se hace indispensable que los médicos y alcaldes de barrio den parte de todos los niños que padezcan dicha enfermedad como igualmente de los que no estén vacunados (33). El 31 de octubre la Junta Superior de Sanidad informa sobre «los cristales de virus que ha recibido de la Institución Filantrópica de Londres, para vacuna» (34).

Era evidente que la vacunación debió llevarse a cabo, lo que no podemos saber es hasta qué punto y durante cuánto tiempo. La preocupación de las autoridades era natural, bastantes niños debieron morir ese año y también en los anteriores.

Los acontecimientos políticos vinieron a complicar aún más la situación de la ciudad. La ocupación de España por los Cien Mil Hijos de San Luis, fue condenada por las autoridades que adoptaron diversas medidas para defender la plaza, proveyéndola de víveres y pidiendo al vecindario seiscientas camas completas para socorrer y proveer al Hospital Militar de San Fernando. El Cabildo de 21 de junio acuerda obligar a los vecinos a contribuir cada uno con una cama, con el fin de acuartelar a toda la tropa de la guarnición (35). Las contribuciones que pagó Alicante en los meses de junio y julio, unidas a otros gastos que hizo pa-

(32) NADAL, J.: «La población española (s. XV| al XX)», pág. 113.

(33) A.M.A. Libro 116.

(34) Ibid.

(35) A.M.A. Libro 117. 
ra atenciones de guerra ascendieron a más de 400.000 reales, sin contar los 130.000 que satisfizo por una contribución extraordinaria para todo el pais. Diversas personas pudientes emigraron para no pagar más. La plaza se entregó, por fin, el 11 de noviembre.

\section{5. - 1824-1832: CRISIS DE SUBSISTENCIAS.}

Con el cambio de sistema político los problemas siguieron siendo los mismos. El estado de los campos era deplorable al finalizar el año 1824. El 28 de julio de 1825 el Ayuntamiento discutió la conveniencia o no de permitir la entrada de granos extranjeros a causa de la carestía de pan y para que no subieran los precios, en beneficio general del pueblo (36). La idea sé desestimó. En los dos años siguientes se realizaron diversas rogativas y en octubre de 1827 el Ayuntamiento tiene enormes dificultades en la recaudación del impuesto de la sal y el equivalente (37). El año 1828 presenta un panorama crítico: rogativas en marzo para implorar la lluvia y falta de agua no sólo para el riego sino para beber los pueblos y caseríos (38). Igual calamidad sufrió el término municipal en 1829. El 22 de marzo se acuerda hacer rogativas al Santísimo Rostro. El estado de miseria era tal que la traslación de la reliquia a la Iglesia de San Nicolás se hizo en secreto «pàra evitar gastos que no pueden costear los fondos públicos, ni soportar el vecindario por el estado de pobreza en que se halla». El 24 de julio se acordó pedir al Sr. intendente que se sirviera rebajar el acopio de sal de la ciudad a 1.300 fanegas, atendida la miseria general y la continua emigración de los vecinos (39).

Alicante se despoblaba. Según escrito del intendente de Valencia, con fecha 13 de enero de 1830, al Ayuntamiento alicantino el empadronamiento practicado por el administrador de rentas, arrojó la cantidad de seiscientas familias menos que el año anterior. En abril se efectuaron nuevas rogativas por la sequía. También en el año 1831 se celebran rogativas en los templos, y desde marzo hasta diciembre, el Cabildo no olvida oficiar a su homónimo eclesiástico, para que añada en las misas la colecta pro-pluvia (40). No es difícil comprender cómo la crisis provocada por la sequía iba a ser el preludio de la crisis epidémica que se avecinaba.

(36) A.M.A. Libro 119.

(37) A.M.A. Libro 121.

(38) A.M.A. Libro 122.

(39) A.M.A. Libro 123.

(40) A.M.A. Libro 125. 


\section{6. - 1833-1834: ESTADO SANITARIO Y EPIDEMIA COLERICA DE 1834.}

En marzo de 1833 las cosechas vuelven a estar en peligro. Las pertinaces sequías hicieron que el Ayuntamiento y los hacendados fijaran seriamente su atención en la conveniencia de construir un canal para aprovechar las aguas sobrantes del júcar. Se intentó poner en práctica en septiembre de 1833, para lo cual se hicieron suscripciones públicas (41).

Cabría preguntarse qué sucedió en los establecimientos sanitarios durante los difíciles años relatados. A esta pregunta responde, en gran medida, el informe de una comisión encargada de inspeccionarlos. En septiembre el Cabildo recibe dicho informe en el que los comisionados afirman que hay Junta de Caridad desde el reinado de Carlos III y que, según las reales órdenes nuevamente expedidas, ésta debe encargarse del cuidado e inspección de los establecimientos pios. Por esta razón se han visitado la Casa se Expósitos y Hospitales existentes en la ciudad. "La inclusa ha sido inspeccionada personalmente por la comisión y ésta no ha podido menos de sensiblizarse y cubrirse de dolor al contemplar un edificio caedizo y medio arruinado, de fábrica muy antigua que por sí proporciona desventajas para el aseo y limpieza tan necesarios absolutamente en estos institutos. Su gobierno interior sigue a la par del edificio, ninguna policía doméstica, todo es asqueroso y sucio. Habitan en esta casa nueve expósitos lactados por amas mal constituidas, gastadas por la miseria, y peor alimentadas. Estas tres nodrizas dan de lactar a los nueve huérfanos... La inclusa, conforme se halla montada no es más que el lugar del dolor, la muerte y no del consuelo y amparo de estos tiernos niños desvalidos».

«Por un quinquenio formado desde el año 1825 hasta 1829 inclusive aparece haber entrado en ella 225 expósitos y resultan finados 177 , - con una media quinquenal de 35 finados por año - y de lo que se colige, que entrando en la inclusa en un año común 44 expósitos, muere casi la totalidad-. A continuación comparan los niños fallecidos en el quinquenio antedicho con los que lo hicieron en ese tiempo en el término parroquial de Santa Maria, y resulta que en dicha parroquia sólo fallecieron la cuarta parte de los nacidos. Los comisionados se preguntan a continuación por qué no es similar la mortalidad infantil en la inclusa que en el término de Santa María. Por último afirman que «si se examina bien el pormenor de la inclusa se hallará un desorden espantoso en

(41) A.M.A. Libro 127. 
su administración, desorden que lo arrojan y patentizan las cuentas de algunos administradores donde resulta la negligencia y la malversación» (42). El informe propone una ayuda económica y la constitución de una sociedad de señoras que ayuden, como ya hubo en 1821 y 1822 . También critican la mala administración de los dos hospitales de la ciudad.

El 9 de marzo de 1834 existía una honda preocupación en el seno del Cabildo. El Cuerpo Municipal sabía que, tras haber hecho su aparición en Francia e Inglaterra, el cólera habia llegado a Vigo en 1833. Poco después Galicia y parte de Andalucía quedaron afectadas y en 1834 el cólera se recrudecía animado por la guerra carlista. No es de extrañar, por tanto, que en reunión fechada el 12 de junio de 1834, el corregidor y Ayuntamiento de Alicante estuviesen muy preocupados ante la posibilidad «de contraer cualquier enfermedad particularmente contagiosa, que desgraciadamente en otros puntos de la península padecen». Las medidas adoptadas fueron las siguientes: Expulsión de los mendigos forasteros. Obligación por parte de los mesoneros, de limpiar las caballerizas y extraer de la ciudad el estiércol, todas las mañanas antes de las seis. Los demás vecinos quedarían sujetos dos veces por semana a la misma obligación. Prohibición de tener animales que no puedan estar en corrales o terrados. Obligación de barrer las fronteras de las casas mañana y tarde, rociándolas con agua limpia. $Y$, por último, se recuerda que en las fuentes no se podrá hacer más uso que el de sacar agua (43).

El 21 de junio un bando del gobernador civil señala que se han establecido cordones militares sanitarios en los pueblos contagiados o gravemente sospechosos y ordena que se abra una suscripción en los pueblos sanos para auxiliar a los contagiados (44). El 23 de junio, ante la invasión del cólera morbo en las ciudades de Murcia y Orihuela se acuerda realizar rogativas públicas y abrir una suscripción de ayuda.

En oficio fechado el día 6 de julio, el gobernador civil exige la entrega de 12.540 reales vellón que existen en las arcas del pósito porque los considera indispensables para el mantenimiento de las Compañías de Seguridad Pública. La Corporación Municipal responde que los fondos de que se trata son tan sagrados que sin una soberana decisión no serán entregados (45). Como se puede comprobar la situación comenzaba a ser tensa y cada autoridad creía obrar correctamente.

El 22 de agosto los temores se han hecho realidad y «con motiva de las enfermedades sospechosas que, por desgracia se padecen en la

(42) Ibid.

(43) A.M.A. Libro 128.

(44) $B$ (oletín $O(f i c i a l)$ de la $P$ (rovincia), $N^{\circ} 23$, año 1834.

(45) A.M.A. Libro 128. 
ciudad y de las que han fallecido algunas personas, para evitar su propagación por el roce ha resuelto el Ayuntamiento que cesen las rogativas que se hacían al Stmo. Rostro» como también el resto de funciones religiosas previstas. Más adelante se prohibe la venta de «toda clase de higos, manzanas, agrios, pepinos y alficoces y demás frutas que no estén perfectamente sazonadas». Por último se señala lo crecido que es el número de presos que se hallan en las Reales Cárceles que «si por desgracia llegase a ser invadida van a perecer por la falta de localidad y aseo que es indispensable». Se acordó oficiar al corregidor para que los presos de la clase de pena capital fuesen trasladados al Castillo de Santa Bárbara, mientras que los que existan por causas políticas o por delitos leves fuesen puestos en libertad bajo las precauciones requeridas (46).

Sería interesante, sin embargo, conocer algunas medidas de las que se tomaron para prevenir la epidemia y la normativa sanitaria que se invocó a la hora de establecer el sistema de cordones sanitarios. En este sentido el 3 de julio se publicó un bando en el que el gobernador militar y político de la plaza y gobernación y presidente de la Junta de Sanidad hacía saber que la enfermedad contagiosa se acercaba a Alicante $y$, en consecuencia, con arreglo a la Real Orden de 11 de Octubre de 1804: "Toda persona que burlando la vigilancia de los cordones los quebrantase, o translimitase la línea de observación, sufra irremisiblemente la pena de muerte y quemados los géneros o efectos contumaces que lleve consigo, y que la misma pena se imponga a todo vecino que admitiese en sus casas a dichas procedencias» (47).

En el suplemento al B.O.P. del Domingo, 27 de julio, la Junta Municipal de Sanidad de Alicante determina lo siguiente:

«1. - Desde el día 28 quedará interrumpida por tierra la libre comunicación de esta capital con los pueblos de su provincia, y cualquier persona que pretenda introducirse en ella deberá previamente sujetarse a una observación y expurgo de nueve días, siempre que su procedencia no fuese de un pueblo infestado. 2. - Para la observación de que habla el artículo anterior, quedan establecidos lazaretos a cargo de uno de los vocales comisarios de la Junta. 3. - Será libre la exportación de toda clase de géneros sin otra circunstancia que la de evitarse en la operación todo contacto físico con las personas de la parte exterior de la línea. 4. - La importación o introducción de géneros y efectos insusceptibles de contagio, lo serán igualmente en los propios términos, y los susceptibles sufrirán una desinfección con arrı glo a las leyes sanitarias, a juicio

(46) Ibid.

(47) B.O.P. N²9, año 1834. 
prudente de los facultativos de la Junta. 5. - Quedan establecidos los puntos llamados de la Goteta, Huerto de Riera y Florida para mercados $y$ en donde con las precauciones que designase el celador nombrado por la Junta se facilite el comercio y la trajinería» (48).

Además de estas medidas para preservar el contagio aparecen en los sucesivos boletines oficiales de la provincia numerosos artículos relativos a métodos curativos del cólera morbo. Los métodos son para todos los gustos, y por supuesto, casi todos «infalibles». Suponemos que las autoridades permitirían su publicación considerando que podía dar la casualidad de que alguno hiciese efecto $o$, al menos, para que el vecindario creyera que había posibilidad de escapar de la terrible enfermedad utilizando el que mejor le pareciese.

Uno de los métodos, propugnado por un licenciado sevillano, se basa en el consumo de aceite común y gran cantidad de agua. Otros recomiendan el opio y la morfina. Un médico de Murcia afirma que el agua de malvas y el aceite son imprescindibles. El médico de Callosa del Segura opina que la enfermedad no es contagiosa y recomienda frotaciones con un cepillo en toda la columna vertebral, piernas y brazos con éter sulfúrico en forma de aspersión, sangrías en el pie y golpes de sanguijuelas en el estómago, agua de nieve abundante entre los alimentos $y$, en último caso, hacer uso del agua de algarrobas en ayudas y por bebida. El cura de Rafal recomienda aceite y té. Un médico de Orihuela lo soluciona todo sangrando el brazo y «con un gran golpe de sanguijuelas en la región epigástrica», luego hace tomar al enfermo agua de coca natural o cocimiento de cebada y, por último, el agua gomosa completa la «curación». Un médico del ejército inglés residente en Jerez prescribe el aseo personal, no tomar frutas y vegetales crudos, ir abrigados, ventilar bien las casas, etc. Otro método consiste en tomar limonadas de ácido sulfúrico o aceite de vitriolo (49).

No es necesario apuntar que la medicina no había progresado lo suficiente en Europa como para poder determinar el agente causante del cólera. Es bien sabido que hasta finales de siglo no se conoció la causa y la vacuna apropiada para el cólera. En la década de 1830 todavía se discutía a nivel nacional e internacional si el cólera era contagioso. Esto es importante porque, según se calificara a la enfermedad, así debian ser las medidas sanitarias tomadas frente a ella. El Boletín Oficial de la Provincia del 13 de Agosto pública un artículo sin firma que vamos a resumir. Dice así:

(48) B.O.P. Suplemento: 27 de Julio, 1834

(49) B.O.P. N ${ }^{\circ} 25-33$. 
«Hasta el presente la opinión pronunciada por algunos médicos ingleses y franceses acerca del no contagio del cólera morbo no reconoce más fundamento que el que les ha sugerido su ingenio harto abundante en ideología, contrariando lo que la experiencia demuestra. Sin embargo que profesores respetables han asentado el contagio del cólera, no se les ha oído ni seguido... Nuestra opinión es que el cólera es contagioso, y para probarlo decimos: ¿quién introdujo el cólera en Polonia sino los ejércitos rusos?, ¿quién en Francia sino los polacos emigrados?, ¿quién en Portugal sino la expedición que salió de Francia para Oporto?, ¿y quién en España sino el roce y comunicaciones que produjo la emigración de varios partidarios de don Miguel, que se trasladaron a las inmediaciones de Ayamonte y Huelva...? ¿ ¿y últimamente en Murcia no se ha introducido por las comunicaciones y roces con individuos, que procedentes de los puntos infestados de Andalucía conservaban el germen del mal en sus vestidos y efectos, y de aquí por comunicaciones y relaciones se ha establecido en Orihuela y demás pueblos de esta provincia? Estamos finalmente persuadidos que los misioneros del no contagio está convencidos de que es contagioso el cólera, sin embargo sus intereses particulares los prefieren al bien general, y obran contra su propia conciencia. Penétrese el público de cuanto llevamos dicho y aplaudirá las medidas sanitarias adoptadas en esta ciudad" (50).

No podemos dejar de consignar que los problemas a la hora de afrontar los problemas derivados de la epidemia eran similares a nivel nacional. $Y$, como es lógico, lo que se establecía para toda la nación repercutía en las provincias y ciudades.

En España los esfuerzos por una mejor sanidad fueron continuos desde el comienzo del ochocientos. Liberales y absolutistas veían en una rigurosa legislación el remedio contra la fiebre amarilla y la asechanza de la peste bubónica. En 1820 el monarca encargó a una Junta que estructurara y redactara un cuerpo jurídico sobre la sanidad del reino. El proyecto se discutió en la legislatura de 1822 , pero fue rechazado. Las causas fueron diversas pero la primera fue que la mayoría de la Cortes no creian en el contagio o, al menos, no se atrevían a afirmarlo. Es sorprendente que sean anticontagionistas los galenos residentes en las zonas más afectadas por la fiebre amarilla, Cádiz y Barcelona. Admitir el contagio supondría el aislamiento de los enfermos, penosa paralización del comercio y la vida de las grandes poblaciones como Cádiz o Barcelona. El proyecto de código sanitario articulaba minuciosamente todo lo

(50) B.O.P. N 39 , año 1834. 
relativo a patentes marítimas, visitas y controles, lazaretos, expurgos, cordones, etc. (51).

Dejada constancia de los problemas gubernamentales en el orden sanitario volvamos a Alicante. Como ya señalamos anteriormente, la epidemia llegó a la ciudad y el 23 de agosto la Junta Municipal de Sanidad dispone que se retiren los cordones sanitarios y se permita la comunicación con todos los pueblos (52). Por si el azote colérico no fuera poco, el intendente de la provincia de Valencia exige a las justicias y Ayuntamiento de Alicante que paguen inmediatamente todas las cantidades que deban. Más adelante afirma que las contribuciones son imprescindibles para sostener al ejército que defiende el trono de Isabel II.

El 16 de septiembre es leído un oficio del gobernador civil, en el que consta que Su Majestad la Reina Gobernadora ha destinado una cantidad a la ciudad. Pero en atención a que la enfermedad descendia, los socorros en comida y dinero eran suficientes y a que después de cantado el Te-deum había que socorrer a gran número de huérfanos y otros desgraciados se resuelve unánimemente reservar la cantidad, 11.000 reales vellón, para más adelante.

Según el estado de la población, firmado el 24 de Diciembre de 1834, habían fallecido 830 personas (53). Jover establece el número de fallecidos en 603 personas (54). Por bando del Gobernador y Presidente de la Junta Municipal de Sanidad sabemos que la epidemia cesó el día 2 de Octubre. No obstante se prohibió pernoctar en la ciudad a los emigrados que intentasen regresar (55). El día 8 de Octubre se declaró a la ciudad en el más perfecto estado de salud y el día 12 se celebró un solemne Te-Deum en acción de gracias al Todopoderoso (56).

Sin embargo el estado de los hospitales era desastroso. En reunión celebrada el 24 de octubre, un diputado del Ayuntamiento manifestó «la nulidad de los Hospitales de la Caridad y San Juan de Dios con que no podía contarse para nada», pues, o no admitían enfermos o tardaban demasiado en admitirlos (57). Ante esta situación el 5 de noviembre se creó una Comisión directiva de Beneficencia con amplias atribuciones para introducir las reformas que reclamaban los hospitales y demás asilos piadosos (58).

(51) PESET, M. y J.L.: «Muerte en España», pág. 216.

(52) B.O.P. N ${ }^{\circ} 42$, año 1834.

(53) A.M.A. Libro 129.

(54) JOVER, N.C.: Op. cit., pág. 167.

(55) B.O.P. N ${ }^{\circ} 54$, año 1834.

(56) A.M.A. Libro 129.

(57) lbid.

(58) JOVER, N.C.: Op. Cit., pñág. 167 y ss. 


\section{7. - 1835-1850: CRISIS DE SUBSISTENCIAS Y NORMAS SANITARIAS}

El año 1835 comienza con las consabidas colectas pro-pluviam, sin tener más datos sobre la situación municipal de ese año. En 1836 se realizan trabajos de desestanque de aguas putrefactas en la partida de $\mathrm{Ba}$ bel, La Goteta, tierras del Barón de Finestrat, La Alcoraya y Rebolledo.

La Guerra Carlista vino a aumentar los quebraderos de cabeza de la Corporación que hizo lo posible por ayudar a las familias que venían a refugiarse en la ciudad por temor a las bandas carlistas (59).

Durante 1838 la Junta Municipal de Beneficencia se queja amargamente de la falta de fondos y exige que contribuyan a su mantenimiento todos los pueblos de la provincia, puesto que se traen a la capital un gran número de expósitos de distintos pueblos.

La situación de la ciudad y alredores tuvo que ser muy crítica y el pillaje se enseñoreó de la huerta y campo de la ciudad. El Cabildo acordó, 9 de junio, crear guardas de campo para que contuviesen los desórdenes que causaban los que se dedicaban al robo de frutas y demás, sin dar estipendio alguno por ello.

Durante los meses de septiembre, octubre y noviembre las protestas de la Junta Municipal de Sanidad son permanentes. El 14 de diciembre, la Junta afirma que los niños están en peligro de muerte. El Ayuntamiento se reune con el presidente de la Diputación y acuerdan una ayuda de 5.500 reales vellón, 4.000 de los cuales pagaría la Diputación (60).

El 23 de mayo de 1840 el Ayuntamiento, en respuesta a un oficio del intendente de la provincia, afirma que no puede pagar la cantidad de 200.000 reales vellón a cuenta de lo que debe de la contribución de guerra. Ni tampoco los 100.000 que posteriormente le piden. Por último se acuerda entregar lo que se recogiese de la recaudación que se estaba efectuando (61). Como podemos observar los problemas hacendísticos de la Corporación eran graves y ello repercutía ostensiblemente en la política sanitaria de la misma.

El 11 de mayo de 1841 se constata la pérdida de todas las cosechas del campo y huerta "a causa de la sequía del año pasado y del presente» (62). El 2 de abril de 1842 es leído un oficio del intendente en el que se impele al Ayuntamiento a que ingrese en tesorería el descubierto por la extraordinaria guerra de 180 millones. El Cabildo acuerda contestar que

(59) A.M.A. Libro 130.

(60) A.M.A. Libro 132.

(61) A.M.A. Libro 134.

(62) A.M.A. Libro 135. 
se está procediendo a los apremios pero que el cobro presentaba muy serias dificultades por la falta de cosechas durante cuatro años consecutivos. En oficio de 22 de septiembre, la Intendencia expone que se le adeudan, desde 1834, por parte del municipio, 880.392 rs. $23 \mathrm{mrs}$. vellón. El Ayuntamiento sólo reconoce 592.160 rs. 6 mrs. vellón e indica que seguirá excitando el celo de los contribuyentes por si alguno podía pagar (63).

Observamos que la Corporación se tomaba con calma las cuestiones de hacienda. Calma a todas luces comprensible en el estado crítico en que se encontraba. En reunión fechada el 23 de mayo de 1843, el jefe político preguntó al Cabildo si se había adelantado algo respecto a la suscripción para los damnificados por la inundación del Centro. A este respecto se le hizo presente que «los males de este pais eran sin duda alguna mucho mayores, puesto que cuatro años, incluso el presente de sequía continuada y falta de cosechas... habían cundido la miseria en la población y obligado a gran parte de ella a emigrar a otras provincias y al extranjero, por lo cual el Ayuntamiento había juzgado infructuoso y aún más conflictivo, hacer gestión alguna en el particular» (64). Su señoría convino en ello.

Fueron años duros en todos los aspectos. En este sentido un proyecto de verdadera trascendencia, concebido para remediar en sustancia el problema agrícola alicantino; fue el de la canalización de las aguas sobrantes del río Júcar, medida eficiente que no pudo realizarse a causa de las diferencias entre Valencia y Alicante. La Diputación de Alicante, primero -18 de Agosto de 1842 - y luego el Ayuntamiento - 27 del mismo mes y año- se dirigen a S.A. El Regente, solicitando dicha canalización uen beneficio de un vasto territorio estéril y pobre hoy por la falta de aguas». He aquí algunos interesantes párrafos pertenecientes a esta exposición del Ayuntamiento».

"La provincia de Alicante está poblada; pero ni su población es rica ni agrícola, es, en toda la costa, pescadora, y la generalidad de ella y del interior, miserable... Hubo un tiempo en que la barrilla... surtía los mercados extranjeros y recompensaba con prodigalidad los sudores del labrador. Francia encontró la soda facticia en 1810 , y la barrilla ha desaparecido de esta provincia en que ya apenas se la conoce... Los vinos, tanto de regalo como comunes, han experimentado, a su vez, los efectos de la legislación, de la moda y de los progresos de la agricultura. Italia ha prohibido la introducción de los primeros. Los mercados de la

(63) A.M.A. Libro 136.

(64) A.M.A. Libro 137. 
Inglaterra dan la preferencia a los de Jerez y Málaga; y generalizado en toda Cataluña el cultivo de la viña, al paso que las segundas rivalizan en calidad con las de esta provincia, éstas no pueden competir por su precio en los mercados de Europa ni América... ¿Dónde está la riqueza de una provincia que ha visto emigrar de su suelo tres mil habitantes en siete meses, mil quinientos de los cuales pertenecen a la ciudad de Alicante y su territorio?... sólo la miseria pudiera producir actos tan poco conformes a la humana naturaleza» (65).

Pero no sólo las cuestiones económicas y sociales preocuparon a las autoridades. También se tuvo muy en cuenta el mantenimiento de una adecuada normativa sanitaria, tanto más útil y necesaria, cuanto más crítica e insostenible se hacía la situación general de la ciudad. En este sentido y por acuerdo del señor jefe superior político y resto de la Corporación, se hizo público, en febrero de 1842 un "Bando de buen gobierno para la Muy Ilustre y Siempre Fiel Ciudad de Alicante» que contemplaba apartados tan importantes como la salubridad, comodidad $y$ limpieza.

En su articulado se establecen normas, prohibiciones y multas. Así leemos que la extracción del estiércol debía hacerse a unas horas determinadas, sacándolo de la población y depositándolo en puntos señalados. El estiércol y escombros no se podían verter por las calles por lo que los carros y acémilas debían estar preparados convenientemente. Se prohibía lavar en sitio alguno de los que conducen aguas a la ciudad y en las inmediaciones del matadero. No se podía criar en el interior de la población ganado de cerda. Antes de las diez de la noche no podrían vaciarse las balsas de los huertos contiguos a la ciudad. Los caballos muertos, mulas y demás bestias de carga debían ser enterrados en Babel, en una zanja de seis palmos al menos de profundidad. No se debían limpiar ollas y otros efectos en los pilones de las fuentes, verter en ellos aguas sucias o lavarse las personas. Todo perro debería llevar un collar en el que se hallara escrito el nombre del dueño, sin lo cual sería muerto cuando la autoridad lo dispusiese. Toda res destinada al mercado público debía hallarse sana y entrar por sus pies al matadero. El pescado presentado al mercado debía ser fresco. Y, por regla general, todo comestible en estado de insalubridad sería quemado o arrojado al mar.

El 3 de junio de 1843 la Corporación constata el peligro que encierran las aguas estancadas en el barranco de La Goteta y acuerda eliminarlas antes de que llegase la estación calurosa a fin de evitar las tercianas en

(65) RAMOS, V.: «Historia de la Provincia de Alicante y de su Capital», págs. 265 y ss. 
el barrio de Santa Ana y el Arrabal Roig (66).

El 1844 la situación municipal es lamentable y el 12 de octubre el Cabildo acuerda contestar al capitán general del reino que no se puede instalar un pararrayos en la ciudad por la situación precaria en que ésta se encuentra y que impide realizar las atenciones más primarias (67).

La situación se agravaría en los años siguientes y así, el 24 de febrero de 1847 el Ayuntamiento contesta a una circular del jefe político en los siguientes términos: "Las cosechas de muchos años a esta parte son ningunas en esta capital y su término y de consiguiente en nada contribuyen a satisfacer las necesidades públicas, haciéndose el surtido de granos para el consumo de Andalucía, La Mancha y Castilla. Las existencias no son más que las del consumo diario que con respecto a granos se surte de los puntos anteriormente expresados y de consiguiente no hay relación alguna entre las subsistencias de primera necesidad y la población, siendo escasos los arribos de la providencia únicamente depende en la actualidad la cosecha, según el aspecto de los sembrados. Si llueve lo necesario puede alcanzarse medianía, faltando el agua del cielo se pierde y de consiguiente, ninguna».

El 9 de marzo se trató el problema de la falta de ocupación en la clase jornalera o proletaria «habiéndose llegado al extremo de verse privados de la subsistencia gran número de familias, cuyo mal se agrava más por la subida que el precio del trigo ha experimentado y siendo urgente tomar alguna providencia para evitar y contener los estragos que serían consiguientes si por la causa expresada se desarrollase el hambre». El Ayuntamiento resolvió que, una vez cubiertas sus más precisas atenciones, se destinaran las existencias restantes a dar ocupación al mayor número posible de jornaleros, destinándolos a la composición de caminos y a otras obras de utilidad semejantes. El señor presidente, en reunión celebrada el 16 de mayo, manifestó que el gobierno de Su Majestad quiere que se garantice el orden público, que pudiera alterarse, como ya ha sucedido en otras provincias a pretexto de la carestía y subida del precio del pan. Después de discutir largamente sobre cómo rebajar el alto precio que el trigo tenía, se acuerda permitir la entrada de grano extranjero (68). No hallamos noticias dignas de mención hasta 1850 , en que se vuelve a incidir sobre la calamidad que se experimenta, acordándose rogativas que, como el Ayuntamiento no puede pagar, se subvencionarán mediante colecta por el vecindario (69).

(66) A.M.A. Libro 137.

(67) A.M.A. Libro 138.

(68) A.M.A. Libro 139.

(69) A.M.A. Libro 142. 
La primera mitad del siglo XIX finaliza en una situación de crisis general de la ciudad de Alicante que no encontrará salida hasta la segunda mitad del siglo en que nuevos factores incidirán en el desarrollo de la población.

\section{BIBLIOGRAFIA}

ARTOLA, M.: "La burguesía revolucionaria (1808-1869)». Alianza, Madrid, 1973.

GIL OLCINA, A.: «Explotación y cultivo de las plantas barrilleras en España». Revista de Estudios Geográficos. Tomo 36, 1975.

GIMENEZ LOPEZ, E.: «Alicante en el siglo XVIII». Valencia, 1981.

JOVER, N.C.: «Reseña histórica de la ciudad de Alicante». Edita Agatángelo Soler Llorca, 1978.

NADAL, J.: "La población española (siglos XVI al XX)». Ariel, Barcelona, 1976.

PESET, M. y J.L.: «Muerte en España (política y sociedad entre la peste y el cólera)». Seminarios y Ediciones S.A.

RAMOS, V.: «Historia de la Provincia de Alicante y de su Capital». Ed. Diputación Provincial de Alicante, 1971.

RODENAS VILLAR, R.: "Crisis de subsistencias y crisis politica en Alicante durante la guerra de la Independencia» en JOVER ZAMORA, J.M. y AA.VV.: «El siglo XIX en España». Ed. Planeta, Barcelona, 1974.

VIRAVENS Y PASTOR, R.: «Crónica de la Muy flustre y Siempre Fiel Ciudad de Alicante». Imp. Carratalá y Gadea, Alicante, 1876. 